\title{
Evaluation of the correlation of vasculogenic mimicry, ALDH1, KiSS-1, and MACC1 in the prediction of metastasis and prognosis in ovarian carcinoma
}

\author{
Lan $\mathrm{Yu}^{\dagger}, \mathrm{Bo}$ Zhu ${ }^{\dagger}$, Shiwu Wu*, Lei Zhou, Wenqing Song, Xiaomeng Gong and Danna Wang
}

\begin{abstract}
Background: Recurrence and metastasis are the usual manifestations of treatment failure of epithelial ovarian carcinoma (EOC). Vasculogenic mimicry (VM; blood supply development often seen in highly aggressive cancers), aldehyde dehydrogenase 1 (ALDH1, cancer stem cell biomarker), KiSS-1 (suppressor of tumor metastasis), and metastasis associated in colon cancer-1 (MACC1) are all useful predictive factors for metastasis and prognosis in various cancers. In this study, we analyzed associations among VM, ALDH1, KiSS-1, and MACC1 in EOC, and their respective correlations with clinicopathological characteristics and survival in EOC.

Methods: Positive rates of VM, ALDH1, KiSS-1, and MACC1 in 207 whole EOC tissue samples were detected by immunohistochemistry. Patients' clinical data were also collected.

Results: Levels of VM, ALDH1, and MACC1 were significantly higher, and levels of KiSS-1 significantly lower, in EOC tissues than in benign ovary tumors. Levels of VM, ALDH1, KiSS-1, and MACC1 were associated significantly with tumor/lymph node/metastasis (LNM) grade, implantation, and International Federation of Gynecology and Obstetrics (FIGO) stage, and with patients' overall survival (OS); whereas the KiSS-1+ subgroup had significantly longer OS than did the KiSS-1 - subgroup. In multivariate analysis, high VM, ALDH1 or MACC1 levels, FIGO stage, implantation and low KiSS-1 levels were independently associated with shorter OS in patients with EOC.
\end{abstract}

Conclusions: VM and expressions of ALDH1, KiSS-1, and MACC1 represent promising markers for metastasis and prognosis, and potential therapeutic targets for EOC.

Keywords: Epithelial ovarian carcinoma, VM, ALDH1, KiSS-1, MACC1, Prognosis

\section{Background}

In 2012, epithelial ovarian carcinoma (EOC) was reportedly found in 238,700 newly diagnosed cases of ovarian cancer (OC), and caused 15,1900 deaths [1], making it the fourth most lethal gynecological cancer [2]. The most commonly diagnosed OCs originate from epithelium; only a minority of OCs are from stromal or germ cells [3, 4]. As OC is usually asymptomatic in its early stages, $>80 \%$ of patients diagnosed with $\mathrm{OC}$ in China have advanced-stage

\footnotetext{
* Correspondence: 573448542@qq.com

${ }^{\dagger}$ Equal contributors

Department of Pathology, the First Affiliated Hospital of Bengbu Medical College, Bengbu Medical College, No.287, Changhuai Road, Bengbu 233003, Anhui Province, China
}

disease (e.g., with implantation or ascites). Despite advances in treatment, 5-year survival rates are still poor.

Although vasculogenesis and angiogenesis have been shown to promote tumor growth and metastasis, clinical benefits of anti-angiogenesis therapy for cancers are still unsatisfactory [5]. Treatments that address the other mechanism of tumor blood supply are urgently needed. Maniotis et al. reported a new blood supply phenomenon: vasculogenic mimicry (VM) which are channel-like structures formed by cancer cells [6]. Various highly aggressive cancer cells can mimic endothelial cells to form channellike structures which could convey blood and nutrient, including gallbladder carcinoma [7], lung cancer [8], pancreatic cancer [9], glioblastoma [10], gastric carcinoma 
[11], hepatocellular carcinoma [12], and esophageal carcinoma [13]. VM is composed of highly aggressive tumor cells, rich extracellular matrix, and vessel-like structures. Patients with tumor-associated VM reportedly have poor prognoses and are prone to metastasis [6-13].

Tumor recurrence and metastasis may be related to cancer stem cells (CSCs), also named tumor-initiating cells, which have the ability to self-renew and initiate heterogeneous cancer cells that compose the tumors [14]. They make up a small part of the tumor cell population $[14,15]$, and are closely linked to slow proliferation rates and resistance to chemo- or radiotherapy [16]. CSCs can be isolated from various malignancies, using such markers as CD133, ALDH1, CD44, CD90, ABCG2, and CD117.

Aldehyde dehydrogenases (ALDHs) are found in the cytoplasm, nucleus, and mitochondria [17], and affect

Table 1 Patients characteristics

\begin{tabular}{|c|c|c|}
\hline Patients characteristics & Frequency (n) & Percentage (\%) \\
\hline \multicolumn{3}{|l|}{ Age (years) } \\
\hline$<60$ & 126 & 60.9 \\
\hline$\geq 60$ & 81 & 39.1 \\
\hline \multicolumn{3}{|l|}{ Location } \\
\hline Left & 84 & 40.6 \\
\hline Right & 81 & 39.1 \\
\hline Bilateral & 42 & 20.3 \\
\hline \multicolumn{3}{|l|}{ Size $(\mathrm{cm})$} \\
\hline$<8.0$ & 124 & 59.9 \\
\hline$\geq 8.0$ & 83 & 40.1 \\
\hline \multicolumn{3}{|l|}{ Type } \\
\hline Serous & 159 & 76.8 \\
\hline Mucinous & 28 & 13.5 \\
\hline Endometrial & 13 & 6.3 \\
\hline Clear cell & 7 & 3.4 \\
\hline \multicolumn{3}{|l|}{ Ascite } \\
\hline No & 122 & 58.9 \\
\hline Yes & 85 & 41.1 \\
\hline \multicolumn{3}{|l|}{ Grade } \\
\hline Well & 122 & 58.9 \\
\hline Moderate + poor & 85 & 41.1 \\
\hline \multicolumn{3}{|l|}{ Implantation } \\
\hline No & 128 & 61.8 \\
\hline Yes & 79 & 38.2 \\
\hline \multicolumn{3}{|l|}{ LNM } \\
\hline No & 129 & 62.3 \\
\hline Yes & 78 & 37.7 \\
\hline \multicolumn{3}{|l|}{ FIGO stage } \\
\hline $1+\|$ & 106 & 51.2 \\
\hline$I I I+I V$ & 101 & 48.8 \\
\hline
\end{tabular}

various fundamental biological process, such as proliferation, differentiation, survival, and oxidative stress [18]. ALDH1 is a common marker of CSCs, and a key member of ALDH superfamily. ALDH1 facilitates detoxification and metabolism of many endogenous and exogenous aldehydes, as well as synthesis of retinoic acid [19]. ALDH1 is a candidate biomarker for metastasis and prognosis of pancreatic carcinoma, gastric carcinoma, lung cancer, ovarian cancer, and breast cancer [17-21].

Inactivation of metastasis suppressor genes and activation of metastasis-promoting genes are early events in cancer invasiveness and metastasis. KiSS-1, a suppressor of metastasis, was first identified in melanoma, through analysis of subtractive hybridization [22]. It is located on chromosome 1q32 and encodes a 145-amino-acid protein that is cleaved into a family of KiSS peptins. KiSS-1 can bind to a G-protein-coupled receptor (GPR54 or KiSS-1R) and is believed to affect cell motility, invasion, proliferation, and metastasis [23]. Down-regulation (for example, through homozygous deletion, promoter methylation, or mutation) of KiSS-1 can increase tumor invasion and metastasis [24-26]. However, the precise function of KiSS-1 in tumor metastasis is still unclear. KiSS-1 is also been considered to be a useful marker of metastasis and prognosis.

Metastasis-associated in colon cancer 1 (MACC1) was the firstly identified by Stein et al. in colon cancer in 2009 [27]. MACC1 is a critical regulator of the hepatocyte growth factor/mesenchymal-epithelial transition (EMT) factor (HGF/c-Met) pathway and can control c-Met transcriptional activity by binding to the promoter of the c-Met gene $[27,28]$. In vitro, MACC1 can activate the HGF/cMet signaling pathway to induce EMT, which promotes tumor proliferation, invasion, and dissemination $[29,30]$. In vivo, MACC1 can promote tumor growth and metastasis $[27,31]$. MACC1 has been shown to affect recurrence, metastasis, and prognosis in various cancers [27-31].

Overall, studies of VM, ALDH1, KiSS-1, and MACC1 in association with tumor metastasis and prognosis suggest that these factors affect cancer progression; however, the associations among VM, ALDH1, KiSS-1, and MACC1 in EOC has not been widely reported. In this study, we examined the hypothesis that these factors are mutual correlated and are related to metastasis and prognosis in EOC.

\section{Methods}

\section{Patients and tissue samples}

We collected specimens from all 207 patients (median age: 59.1 years; range: $22-75$ years) who were treated for EOC at the First Affiliated Hospital of Bengbu Medical College, from January 2008 to December 2010, along with 60 samples of benign tumors (serous- or mucinouscystadenoma). Patients who had received preoperative chemo- or radiotherapy, or other anti-cancer therapy, 
were excluded. All tissue samples (including both benign and malignant tumors) were obtained with patients' consent. This study was approved by the ethics committee of Bengbu Medical College and performed in accordance with the guidelines of the Declaration of Helsinki (No.BBMCEC2012063).. We included patients for whom we had complete pathological, clinical, and follow-up data (sampled at 6-month intervals by phone, mail, or e-mail). Overall survival (OS) was calculated from the patient's surgery date to her death date or December 2015 (mean OS: 51.6 months; range: 6-95 months). As 20 patients had lost contact due to relocation, the cohort for survival data was 187 patients. Tumor-node-metastasis (TMN) stage was assessed according to the $2014^{\text {th }}$ edition of the International Federation of Gynecology and Obstetrics (FIGO). Tumors were graded according to World Health Organization standards (Table 1).

\section{Immunohistochemistry}

Immunohistochemistry was performed according to the Elivision ${ }^{\mathrm{TM}}$ Plus detection kit instructions (Lab Vision, USA). All EOC and control tissues were fixed in 10\% buffered formalin and embedded in paraffin. Continuous $4-\mu$ m-thick sections were cut. All EOC and control sections were deparaffinized and dehydrated in xylene and graded alcohol, then washed with phosphate buffer saline (PBS, pH 7.2). Endogenous peroxidase activity was blocked by incubating sections in methanol containing $3 \% \mathrm{H} 2 \mathrm{O} 2$ for $10 \mathrm{~min}$ at room temperature (RT), then placed in citrate buffer ( $\mathrm{pH}$ 6.0) and heated to $95{ }^{\circ} \mathrm{C}$ for antigen repair for $30 \mathrm{~min}$. After several washes with PBS, all sections were quenched with goat serum at RT for $30 \mathrm{~min}$, then incubated with mouse monoclonal antibody against human CD34 (Abcam, USA), ALDH1 (Abcam), KiSS-1 (Santa Cruz Biotechnology, Santa Cruz, CA, USA), or rabbit polyclonal antibody against human MACC1 (Santa Cruz Biotechnology) at $37^{\circ} \mathrm{C}$ for $1 \mathrm{~h}$. All samples were conducted periodic acid-Schiff (PAS) CD34 dual staining to determine endothelial cells in glycosylated basement membranes of vessels, as well as vessel-like (VM) structure [8]. Furthermore, we found no necrosis and hemorrhage in tumor tissue near the VM structures.

A modified Yue's method was used to assess VM in the EOC tissues and the control tissues [32]. All specimens were counterstained with hematoxylin, dehydrated, air-dried, and mounted. ALDH1+, MACC1+ and KiSS-1 + stains were all mainly seen in tumor cell cytoplasm.

\section{Evaluation of staining}

Staining results were assessed semi-quantitatively by two independent pathologists who were blind to patients' clinical and follow-up data. Ten high-power-fields (HPF) from different areas of each EOC slide were analyzed to avoid any intratumoral heterogeneity of antibody expression. Staining results were scored according to intensity (none: 0 ; weak: 1 ; moderate: 2 ; strong: 3 ) and extent (<11\%: 1 ; $11-50 \%$ : 2; 51-75\%: 3; >75\%: 4). Intensity and extent scores were then multiplied to yield final scores that ranged $0-12$. Scores $\geq 3$ were considered positive. For sections that were positive for all three of ALDH1, KiSS-1, and MACC1, an average of the final score of each section was taken.

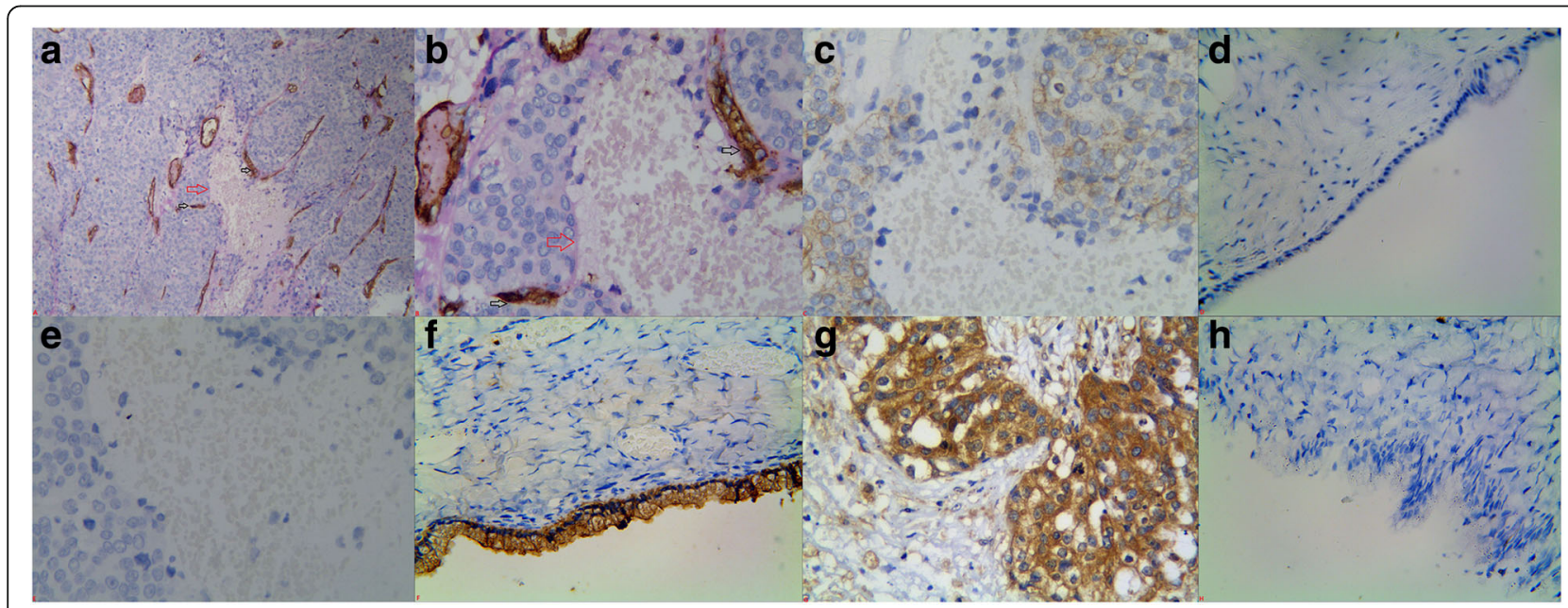

Fig. 1 Positive staining of VM, or ALDH1, or KiSS-1, or MACC1 in epithelial ovarian carcinoma or the control tissue. a Positive staining of VM in the EOC tissue (400 magnification, red arrow is VM structure, black arrow is microvessel); b Positive staining of VM in the EOC tissue (400 magnification, red arrow is VM structure, black arrow is microvessel); c Positive staining of ALDH1 in the cytoplasm of cancer cells (400 magnification); $\mathbf{d}$ Negative staining of ALDH1 in the control tissue (100 magnification); e Negative staining of KiSS-1 in the EOC tissue (400 magnification); $\mathbf{f}$ Positive staining of KiSS-1 in the cytoplasm of the control cells (100 magnification); $\mathbf{g}$ Positive staining of MACC1 in the cytoplasm of cancer cells (400 magnification); $\mathbf{h}$ : Negative staining of MACC1 in the control tissue (100 magnification, $\mathbf{a}, \mathbf{b}, \mathbf{c}$, e are serial sections) 


\section{Statistical analysis}

Associations between clinicopathological characteristics and VM, ALDH1, KiSS-1, or MACC1 were compared using Fisher's exact test or Chi-square test. Associations between VM, or ALDH1, or KiSS-1, or MACC1 was compared using Spearman's coefficient test. Effects of VM, ALDH1, KiSS-1, or MACC1 on survival were determined by univariate and multivariate analyses. Independent prognostic factors were determined using the Cox regression model for multivariate analysis. The Kaplan-Meier method with log-rank test for univariate OS analysis was used to evaluate associations between $\mathrm{VM}+$, ALDH1+, KiSS-1+, or MACC1+ results and clinicopathological characteristics, using SPSS 19.0 software for Windows (Chicago, IL). $P<0.05$ was considered significant.

\section{Results}

Associations between VM, ALDH1, KiSS-1 and MACC1 expressions and clinicopathological characteristics

To evaluate the contributions of VM, ALDH1, KiSS-1, and MACC1 to EOC, the results thereof were immunohistochemically evaluated for both EOC and control tissue samples. These data were then compared to patients' clinicopathological characteristics. The rate of $\mathrm{VM}+$ findings (small vessel, which is like a channel in EOC, the channel was PAS-positive but CD34-negative. The VM structure

Table 2 The correlation between VM, or ALDH1, or KiSS-1, orMACC1 and clinicopathological characteristics in epithelial ovarian carcinoma

\begin{tabular}{|c|c|c|c|c|c|c|c|c|c|c|c|c|}
\hline \multirow[t]{2}{*}{ Variable } & \multicolumn{2}{|l|}{ VM } & \multirow[t]{2}{*}{$P$} & \multicolumn{2}{|l|}{ ALDH1 } & \multirow[t]{2}{*}{$P$} & \multicolumn{2}{|c|}{ KiSS-1 } & \multirow[t]{2}{*}{ P } & \multicolumn{2}{|l|}{ MACC1 } & \multirow[t]{2}{*}{$P$} \\
\hline & Negative & Positive & & Negative & Positive & & Nega & Positive & & Negative & Positive & \\
\hline Age (years) & & & 0.690 & & & 0.664 & & & 0.855 & & & 0.839 \\
\hline$<60$ & 79 & 47 & & 46 & 80 & & 84 & 42 & & 50 & 76 & \\
\hline$\geq 60$ & 53 & 28 & & 32 & 49 & & 53 & 28 & & 31 & 50 & \\
\hline Location & & & 0.727 & & & 0.737 & & & 0.504 & & & 0.422 \\
\hline Left & 53 & 31 & & 29 & 55 & & 54 & 30 & & 29 & 55 & \\
\hline Right & 54 & 27 & & 32 & 49 & & 52 & 29 & & 36 & 45 & \\
\hline Bilateral & 25 & 17 & & 17 & 25 & & 31 & 11 & & 16 & 26 & \\
\hline Size $(\mathrm{cm})$ & & & 0.570 & & & 0.614 & & & 0.749 & & & 0.879 \\
\hline$<8.0$ & 81 & 43 & & 45 & 79 & & 81 & 43 & & 48 & 76 & \\
\hline$\geq 8.0$ & 51 & 32 & & 33 & 50 & & 56 & 27 & & 33 & 50 & \\
\hline Type & & & 0.155 & & & 0.144 & & & 0.856 & & & 0.238 \\
\hline Serous & 97 & 62 & & 55 & 104 & & 107 & 52 & & 61 & 98 & \\
\hline Mucinous & 20 & 8 & & 16 & 12 & & 17 & 11 & & 15 & 13 & \\
\hline Endometrial & 8 & 5 & & 5 & 8 & & 9 & 4 & & 3 & 10 & \\
\hline Clear cell & 7 & 0 & & 2 & 5 & & 4 & 3 & & 2 & 5 & \\
\hline Ascite & & & 0.952 & & & 0.247 & & & 0.413 & & & 0.097 \\
\hline No & 78 & 44 & & 42 & 80 & & 78 & 44 & & 42 & 80 & \\
\hline Yes & 54 & 31 & & 36 & 49 & & 59 & 26 & & 39 & 46 & \\
\hline Grade & & & 0.003 & & & 0.040 & & & 0.001 & & & 0.001 \\
\hline Well & 88 & 34 & & 53 & 69 & & 70 & 52 & & 59 & 63 & \\
\hline Moderate + poor & 44 & 41 & & 25 & 60 & & 67 & 18 & & 22 & 63 & \\
\hline Implantation & & & 0.028 & & & $<0.001$ & & & 0.001 & & & $<0.001$ \\
\hline No & 89 & 39 & & 61 & 67 & & 74 & 54 & & 66 & 62 & \\
\hline Yes & 43 & 36 & & 17 & 62 & & 63 & 16 & & 15 & 64 & \\
\hline LNM & & & 0.044 & & & 0.013 & & & 0.025 & & & 0.005 \\
\hline No & 89 & 40 & & 57 & 72 & & 78 & 51 & & 60 & 69 & \\
\hline Yes & 43 & 35 & & 21 & 57 & & 59 & 19 & & 21 & 57 & \\
\hline FIGO stage & & & $<0.001$ & & & 0.004 & & & $<0.001$ & & & $<0.001$ \\
\hline$I+\|$ & 81 & 25 & & 50 & 56 & & 54 & 52 & & 58 & 48 & \\
\hline$I I I+I V$ & 51 & 50 & & 28 & 73 & & 83 & 18 & & 23 & 78 & \\
\hline
\end{tabular}


pattern included tubular, linear, and network, et al.) in the EOC samples $(36.2 \% ; 75 / 207)$ was significantly higher than that in the control tissues $(0 \% ; 0 / 60 ; P<0.001$; Fig. 1 a, b). VM in EOC was positively associated with tumor grade, LNM, implantation, and FIGO stage, but not patient age, tumor location, size, type, or ascites (Table 2).

As with VM, ALDH1+ expression was significantly higher in EOC tissues $(62.3 \%, 129 / 207)$ than in control tissues $(18.3 \%, 11 / 60 ; P<0.001$; Fig. $1 \mathrm{c}, \mathrm{d})$. The rate of ALDH1+ expression in EOC was associated with tumor grade, LNM, implantation, and FIGO stage, but not patient age, tumor location, size, type, or ascites (Table 2).

KiSS-1+ expression was significantly less in EOC tissues $(33.8 \%, 70 / 207)$ than in control tissues $(96.7 \%, 58 /$ 60; $P<0.001$; Fig. 1e, f). The rate of KiSS-1+ expression was inversely related to tumor grade, LNM, implantation, and FIGO stage. No association was found between KiSS-1 expression and patient age, tumor location, size, type, or ascites (Table 2).
MACC1+ expression was significantly higher in EOC tissues $(60.9 \%, 126 / 207)$ than in control tissues $(8.3 \%, 5 /$ 60; $P<0.001$; Fig. $1 \mathrm{~g}$, h). MACC1+ expression was also associated with tumor grade, LNM, implantation and FIGO stage, but not patient age, tumor location, size, type, or ascites (Table 2).

\section{Univariate and multivariate analyes}

Follow-up data demonstrated that OS was significantly shorter in EOC patients with VM+ samples (41.6 \pm 21.1 months) compared with those with VM- $(57.3 \pm$ 22.9 months; log-rank $=19.072, P<0.00$; Fig. 2a). Similarly, OS of ALDH1+ patients (40.4 \pm 19.7 months) was significantly shorter than those of ALDH- patients (70.0 \pm 16.7 months; log-rank $=73.845, P<0.001$; Fig. $2 b)$. The OS of KiSS-1+ patients $(64.6 \pm 21.0$ months $)$ was significantly longer than those who were KiSS-1- $(45.0 \pm$ 21.9 months; log-rank $=29.001, P<0.001$; Fig. 2c). The OS
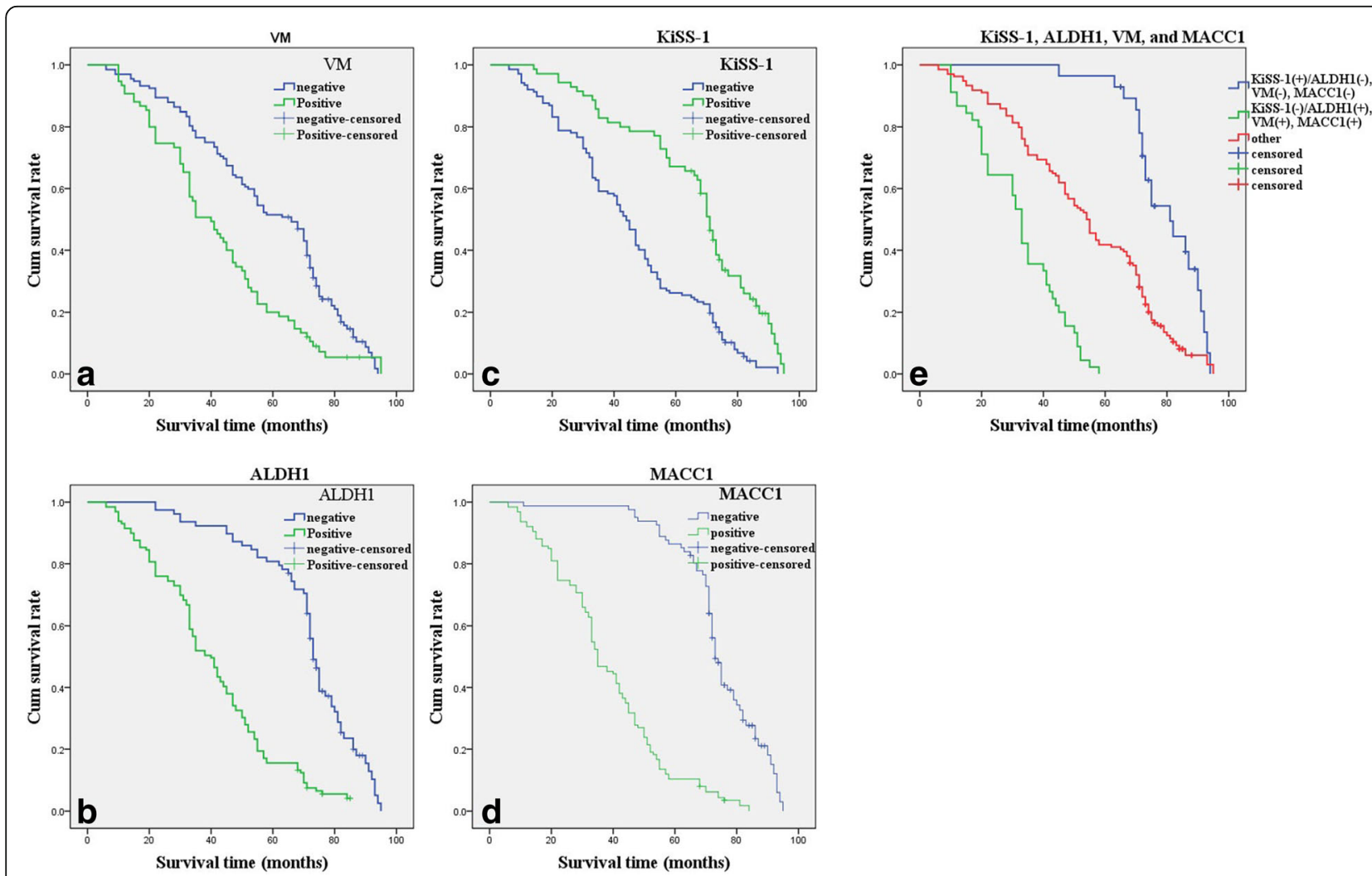

Fig. 2 Kaplan-Meier analysis of the survival rate of patients with epithelial ovarian carcinoma. The $y$-axis represents the percentage of patients; the $x$-axis, their survival in months. a Overall survival of all patients in relation to VM (log-rank $=19.072, P<0.001)$; $\mathbf{b}$ Overall survival of all patients in relation to ALDH1 expression (log-rank $=73.845, P<0.001$ ); c Overall survival of all patients in relation to KiSS-1 expression (log-rank $=29.001, P<0.001$ ); $\mathbf{d}$ Overall survival of all patients in relation to MACC1 expression (log-rank $=118.775, P<0.001$ ). In $\mathbf{a}, \mathbf{b}$, and $\mathbf{d}$ analyses, the green line represents patients with positive expression of $\mathrm{VM}$, or $\mathrm{ALDH1}$, or MACC1 with a trend of worse survival time than the blue line representing the negative VM, or ALDH1, or MACC1 group. In $\mathbf{d}$ analyses, the green line represents patients with positive expression of KiSS-1 with a trend of better survival time than the blue line representing the negative KiSS-1 group. e Overall survival of all patients in relation to the combination of KiSS-1, ALDH1, VM, and MACC1 expression (log-rank $=87.116, P<0.001$ ). The green line represents negative expression of KiSS-1 and positive expression of ALDH1, VM, MACC1 and the blue line represents positive expression of KiSS-1 and negative expression of ALDH1, VM, MACC1. The red line represents other positive or negative expression of the proteins 
Table 3 Results of univariate analyses of overall survival time (OST)

\begin{tabular}{|c|c|c|c|c|}
\hline Variable & $n$ & Mean OS (months) & Log-rank & $P$ value \\
\hline VM & & & 19.072 & $<0.001$ \\
\hline Negative & 132 & $57.3 \pm 22.9$ & & \\
\hline Positive & 75 & $41.6 \pm 21.1$ & & \\
\hline ALDH1 & & & 73.845 & $<0.001$ \\
\hline Negative & 78 & $70.0 \pm 16.7$ & & \\
\hline Positive & 129 & $40.4 \pm 19.7$ & & \\
\hline KiSS-1 & & & 29.001 & $<0.001$ \\
\hline Negative & 137 & $45.0 \pm 21.9$ & & \\
\hline Positive & 70 & $64.6 \pm 21.0$ & & \\
\hline MACC1 & & & 118.775 & $<0.001$ \\
\hline Negative & 81 & $72.7 \pm 13.2$ & & \\
\hline Positive & 126 & $38.0 \pm 18.0$ & & \\
\hline Age (years) & & & 0.869 & 0.351 \\
\hline$<60$ & 126 & $52.8 \pm 23.4$ & & \\
\hline$\geq 60$ & 81 & $50.0 \pm 23.6$ & & \\
\hline Location & & & 1.783 & 0.410 \\
\hline Left & 84 & $46.9 \pm 26.2$ & & \\
\hline Right & 81 & $57.8 \pm 17.4$ & & \\
\hline Bilateral & 42 & $48.9 \pm 25.7$ & & \\
\hline Size (cm) & & & 3.386 & 0.066 \\
\hline$<8.0$ & 124 & $53.5 \pm 24.2$ & & \\
\hline$\geq 8.0$ & 83 & $48.8 \pm 23.3$ & & \\
\hline Type & & & 6.662 & 0.083 \\
\hline Serous & 159 & $51.1 \pm 23.9$ & & \\
\hline Mucinous & 28 & $60.5 \pm 20.8$ & & \\
\hline Endometrial & 13 & $43.5 \pm 19.6$ & & \\
\hline Clear cell & 7 & $42.3 \pm 24.2$ & & \\
\hline Ascite & & & 1.543 & 0.214 \\
\hline No & 122 & $50.3 \pm 22.7$ & & \\
\hline Yes & 85 & $54.5 \pm 24.6$ & & \\
\hline Grade & & & 14.060 & $<0.001$ \\
\hline Well & 122 & $56.5 \pm 23.9$ & & \\
\hline Moderate + poor & 85 & $44.5 \pm 21.0$ & & \\
\hline Implantation & & & 68.810 & $<0.001$ \\
\hline No & 128 & $61.0 \pm 21.2$ & & \\
\hline Yes & 79 & $36.4 \pm 18.6$ & & \\
\hline LNM & & & 9.915 & 0.002 \\
\hline No & 129 & $57.5 \pm 21.6$ & & \\
\hline Yes & 78 & $41.9 \pm 23.3$ & & \\
\hline FIGO stage & & & 50.925 & $<0.001$ \\
\hline $1+\|$ & 106 & $62.2 \pm 22.1$ & & \\
\hline$I I I+I V$ & 101 & $40.5 \pm 19.5$ & & \\
\hline
\end{tabular}

of MACC1+ patients (38.0 \pm 18.0 months) was significantly shorter than those who were MACC1- $(72.7 \pm$ 13.2 months; log-rank $=118.775, P<0.001$; Fig. $2 d$ ). The combination of KiSS-1- expression and ALDH1+, VM+, and MACC1+ expression led to poorer prognoses than did the reverse combination (log-rank $=87.116, P<0.001$; Fig. 2e). In univariate analysis, OS was significantly associated with clinicopathological characteristics, including grade $(P=0.001$, log-rank $=14.060)$, LNM $(P=0.002$, logrank $=9.915)$, implantation $(P<0.001$, log-rank $=68.810)$, and FIGO stage $(P<0.001$, log-rank $=50.925$; Table 3$)$.

Multivariate analysis indicated that $\mathrm{VM}+, \mathrm{ALDH} 1+$, KiSS-1+, and/or MACC1+ specimens, and implantation and FIGO stage, were independent prognostic factors for EOC (Table 4).

\section{Associations among VM, and expression of ALDH1, KiSS-1, and MACC1 in EOC}

Spearman correlation coefficient analysis showed negative associations between KiSS-1+ expression and that of VM $(r=-0.284, P<0.001)$, ALDH1 $(r=-0.224, P=0.001)$, or MACC1 $(r=-0.306, P<0.001)$. Expression of ALDH1 and that of VM $(r=0.150, P=0.030)$ and MACC1 $(r=0.704$, $P<0.001)$ were positively associated, as were VM and MACC1 $(r=0.193, P=0.005$; Table 5).

\section{Discussion}

EOC is a highly heterogeneous cancer, which can interfere with the reproducibility of biomarker evaluation. Therefore, prognostic value of candidate biomarkers must be thoroughly evaluated to ensure their validity. In this study, we found that VM was positively associated with tumor grade, LNM, implantation, and FIGO stage. Moreover, Kaplan-Meier survival analysis showed that VM+ EOC patients had significantly shorter OS than did VM- patients. These results suggest that VM plays a key role in EOC progression and metastasis, and could be a useful biomarker in managing this disease. VM may be responsible for the failure of anti-angiogenesis therapy [33-35]. Our results are consistent with previous studies, including those of OC and other cancers $[8,11,12,36]$.

Table 4 Results of multivariate analyses of overall survival time (OST)

\begin{tabular}{lrllll}
\hline Variable & \multicolumn{1}{l}{$\mathrm{B}$} & $\mathrm{SE}$ & $\mathrm{P}$ & $\mathrm{RR}$ & $95 \% \mathrm{Cl}$ \\
\hline VM & 0.408 & 0.170 & 0.017 & 1.503 & $1.076-2.100$ \\
ALDH1 & 0.621 & 0.241 & 0.010 & 1.860 & $1.160-2.983$ \\
KiSS-1 & -0.371 & 0.181 & 0.041 & 0.690 & $0.484-0.985$ \\
MACC1 & 1.400 & 0.255 & $<0.001$ & 4.057 & $2.460-6.691$ \\
Implantation & 1.009 & 0.191 & $<0.001$ & 2.744 & $1.886-3.992$ \\
FIGO stage & 0.687 & 0.188 & $<0.001$ & 1.987 & $1.376-2.871$ \\
\hline
\end{tabular}


Table 5 Correlation among VM, ALDH1, KiSS-1, and MACC1 in EOC

\begin{tabular}{|c|c|c|c|c|c|c|c|c|c|c|c|c|}
\hline \multirow[t]{2}{*}{ Variable } & \multicolumn{2}{|l|}{ VM } & \multirow[t]{2}{*}{ r } & \multirow[t]{2}{*}{$P$} & \multicolumn{2}{|l|}{$\mathrm{ALDH} 1$} & \multirow[t]{2}{*}{$r$} & \multirow[t]{2}{*}{ P } & \multicolumn{2}{|l|}{ KiSS-1 } & \multirow[t]{2}{*}{ r } & \multirow[t]{2}{*}{$P$} \\
\hline & Negative & Positive & & & Negative & Positive & & & Negative & Positive & & \\
\hline MACC1 & & & 0.193 & 0.005 & & & 0.704 & $<0.001$ & & & -0.306 & $<0.001$ \\
\hline Negative & 61 & 20 & & & 65 & 16 & & & 39 & 42 & & \\
\hline Positive & 71 & 55 & & & 13 & 113 & & & 98 & 28 & & \\
\hline VM & & & & & & & 0.150 & 0.030 & & & -0.284 & $<0.001$ \\
\hline Negative & & & & & 57 & 75 & & & 74 & 58 & & \\
\hline Positive & & & & & 21 & 54 & & & 63 & 12 & & \\
\hline ALDH1 & & & 0.150 & 0.030 & & & & & & & -0.224 & 0.001 \\
\hline Negative & 57 & 21 & & & & & & & 41 & 37 & & \\
\hline Positive & 75 & 54 & & & & & & & 96 & 33 & & \\
\hline
\end{tabular}

ALDH1, an intracellular enzyme that helps detoxify and metabolize many endogenous and exogenous aldehydes, is commonly considered to be a CSC marker in various cancers [17-21]. Among the ALDH1 family subtypes, ALDH1A1 protects tumor cells against various cytotoxic drugs [37], whereas ALDH1A3 may play an important role in progression and metastasis; both are candidate biomarkers of prognosis in many cancer types [38]. ALDH1A3 was considered to be the isoenzyme responsible for ALDH activity and tumorigenicity in tumor cells [39]. In EOC, ALDH1 has been associated with poor prognosis [40] and poor response to chemotherapy [20]. The current study found that positive expression of ALDH1 may affect EOC development, invasion and metastasis, and is associated with poor prognosis. Some other studies showed similar results [17-21, 40].

KiSS-1 is widely regarded as a suppressor of tumor metastasis in various cancers [22-26]. KiSS-1 can inhibit cell motility, invasion, and metastasis [23] and reduce metastatic potential; however, it does not inhibit tumorigenicity [25]. Findings in this study also demonstrated that KiSS-1 expression was significantly lower in EOC tissues than in control tissues, and its expression was inversely associated with tumor grade, LNM, implantation and FIGO stage. In addition, Kaplan- Meier survival indicated that EOC patients with KiSS-1+ specimens had significantly higher survival rates than did KiSS-1- patients. These results suggest that KiSS-1 down-regulation promotes EOC progression and metastasis, which is similar to results of previous studies [22-26, 41].

MACC1 is a key regulator of the HGF/c-Met pathway which reportedly affects tumorigenicity, epithelial-mesenchymal transition (EMT), cell motility, invasion, and metastasis [27, 28, 42]. The current study found that MACC1 expression in EOC tissues was significantly higher than in control tissues. We also found MACC1 overexpression to be positively related to tumor grade, LNM, implantation, and FIGO stage. As with ALDH1,
OS of MACC1+ EOC patients was significantly shorter that for the MACC1- subgroup. Our results are similar to previous studies of EOC [43, 44], which suggests that MACC1 could be a useful biomarker for EOC.

FIGO staging guides therapeutic strategies for patients with EOC, but does not provide clear information about EOC's behavior. Therefore, novel and effective biomarkers to predict EOC behavior, metastasis, and patient prognosis are urgently needed. In this study, multivariate Cox regression analysis indicated that VM, ALDH1, KiSS-1, and MACC1 expression and implantation, as well as FIGO stage, are independent prognostic factors for EOC patients. Our results thus support VM, ALDH1, KiSS-1, and MACC1 as credible biomarkers for EOC, especially in predicting metastasis and prognosis.

Moreover, as ALDH1 is a marker for CSCs, its involvement in CSCs may play an important role in the initiation and progression of EOC. CSCs can induce angiogenesis to provide adequate nutrition and oxygen for rapid tumor growth [45], and can apparently differentiate tumor cells and endothelial cells [46]; thus CSCs can mimic endothelial cells to form VM structures in the host microcirculation system. EMT plays a key role in tumorigenesis and in VM [47-49]. As MACC1 regulates the $\mathrm{HGF} / \mathrm{c}-$ Met signaling pathway, it can promote VM [11]. KiSS-1 can inhibit NF- $\mathrm{KB}$ binding to the MMP9 promoter [50] which degrades the extracellular matrix; whereas decreased KiSS-1 should down-regulate its inhibition of metastasis, thus further promoting invasion and metastasis.

\section{Conclusions}

Our results imply that ALDH1 affects EOC evolution; and that combined detection of VM, ALDH1, KiSS-1, and MACC1 are valuable indicators of metastasis and prognosis in EOC. 


\section{Abbreviation}

ALDH1: Aldehyde dehydrogenase 1; CSC: Cancer stem cells; EMT: Epithelialmesenchymal transition; EOC: Epithelial ovarian carcinoma; FIGO: International Federation of Gynecology and Obstetrics; HGF/c-Met: Hepatocyte growth factor/mesenchymal-epithelial transition; HPF: High power field; LNM: Lymph node metastasis; MACC1: Metastasis-associated in colon cancer 1; OC: ovarian carcinoma; OST: overall survival time; PAS: periodic acid-Schiff; PBS: phosphate buffer saline; RT: room temperature; TIC: tumor initiating cells; VM: vasculogenic mimicry; WHO: World Health Organization

\section{Acknowledgements}

We thank the staff members at the Department of Pathology of the First Affiliated Hospital of Bengbu Medical College for assistance with the data search and project management.

\section{Funding}

This work was supported by the Nature Science Foundation of Anhui Province (No.1708085MH230) and the Nature Science Key Program of College and University of Anhui Province (No.KJ2015A269 and KJ2016A488) and Key projects of support program for outstanding young talents in Colleges and Universities of Anhui Province (No. gxyqZD2016160).

\section{Availability of data and materials}

The datasets during and/or analyzed during the current study are available from the corresponding author on reasonable requests.

\section{Authors' contributions}

WSW, YL, and ZB carried out the design, analysis of pathology and drafted the manuscript. ZL, GXM, and SWQ carried out sample collection and coordination. WDN performed the immunohistochemical staining. All authors read and approved the manuscript.

\section{Competing interests}

The authors declare that they have no competing interests.

\section{Consent for publication}

Not applicable.

\section{Ethics approval and consent to participate}

All tissue samples were obtained with patients writing consent and the study was approved by the ethical committee of Bengbu Medical College and performed in accordance with the ethical guidelines of the Declaration of Helsinki (No.BBMCEC2012063)

\section{Received: 16 September 2016 Accepted: 20 February 2017} Published online: 02 March 2017

\section{References}

1. Torre LA, Bray F, Siegel RL, Ferlay J, Lortet-Tieulent J, Jemal A. Global cancer statistics, 2012. CA Cancer J Clin. 2015:65:87-108.

2. Liu Y, Song N, Ren K, Meng S, Xie Y, Long Q, Chen X, Zhao X. Expression loss and revivification of RhoB gene in ovary carcinoma carcinogenesis and development. PLoS One. 2013;8:e78477.

3. Parking DM, Bray F, Ferlay J, Pisani P. Estimating the world cancer burden: Globocan 2000. Int J Cancer. 2001:94:153-6.

4. Kaku T, Ogawa S, Kawano Y, Ohishi Y, Kobayashi H, Hirakawa T, Nakano H. Histological classification of ovarian cancer. Med Electron Microsc. 2003;36:9-17.

5. Vredenburgh JJ, Desjardins A, Herndon IIJE, Dowell JM, Reardon DA, Quinn JA, Rich JN, Sathornsumetee S, Gururangan S, Wagner M, Bigner DD, Friedman AH, Friedman HS. Phase II trial of bevacizumab and irinotecan in recurrent malignant glioma. Clin Cancer Res. 2007;13:1253-9.

6. Maniotis AJ, Folberg R, Hess A, Seftor EA, Gardner LM, Pe'er J, Trent JM, Meltzer PS, Hendrix MJ. Vascular channel formation by human melanoma cells in vivo and in vitro: vasculogenic mimicry. Am J Pathol. 1999:155:739-52.

7. Zhang JT, Sun W, Zhang WZ, Ge CY, Liu ZY, Zhao ZM, Lu XS, Fan YZ. Norcantharidin inhibits tumor growth and vasculogenic mimicry of human gallbladder carcinomas by suppression of the PI3-K/MMPs/Ln-5Y2 signaling pathway. BMC Cancer. 2014;14:193.

8. Wu S, Yu L, Wang D, Zhou L, Cheng Z, Chai D, Ma L, Tao Y. Aberrant expression of CD133 in non-small cell lung cancer and its relationship to vasculogenic mimicry. BMC Cancer. 2012;12:535
9. Xu X, Yang L, Zheng L, Pan Y, Cao Z, Zhang Z, Zhou Q, Yang B, Cao C. Suberoylanilide hydroxamic acid, an inhibitor of histone deacetylase, suppresses vasculogenic mimicry and proliferation of highly aggressive pancreatic cancer PaTu8988 cells. BMC Cancer. 2014;14:373.

10. Mao JM, Liu J, Guo G, Mao XG, Li CX. Glioblastoma vasculogenic mimicry: signaling pathways progression and potential anti-angiogenesis targets. Biomarker Res. 2015;3:8.

11. Wang L, Lin L, Chen X, Sun L, Liao Y, Huang N, Liao W. Metastasisassociated in colon cancer-1 promotes vasculogenic mimicry in gastric cancer by upregulating Twist1/2. Oncotarget. 2015;6:11492-506.

12. Zhao N, Sun BC, Zhao XL, Wang Y, Meng J, Che N, Dong XY, Gu Q. Role of $\mathrm{BCl}-2$ and its associated miRNAs in vasculogenic mimicry of hepatocellular carcinoma. Int J Clin Exp Pathol. 2015:8:15759-68.

13. Tang NN, Zhu H, Zhang HJ, Zhang WF, Jin HL, Wang L, Wang P, Hu GJ, Hao $B$, Shi RH. HIF-1ainduces VE-cadherin expression and modulates vasculogenic mimicry in esophageal carcinoma cells. World J Gastroenterol. 2014;20:17894-904.

14. Beck B, Blanpain C. Unraveling cancer stem cell potential. Nat Rev Cancer. 2013;13:727-38

15. Alison MR, Islan S, Wright NA. Stem cells in cancer: instigators and propagators? J Cell Sci. 2010:123:2357-68.

16. Frank NY, Schatton T, Frank MH. The therapeutic promise of the cancer stem cell concept. J Clin Invest. 2010;120:41-50.

17. Kim IG, Lee JH, Kim SY, Kim JY, Cho EW. Fibulin-3 negatively regulates ALDH1 via c-MET suppression and increases c-radiation-induced sensitivity in some pancreatic cancer cell lines. Biochem Biophy Res Commun. 2014; 454:369-75.

18. Li X, Xu Q, Fu X, Luo W. ALDH1A1 overexpression is associated with the progression and prognosis in gastric cancer. BMC Cancer. 2014;14:705.

19. Huo W, Du M, Pan X, Zhu X, Li Z. Prognostic value of ALDH1 expression in lung cancer: a meta-analysis. Int J Clin Exp Med. 2015;8(2):2045-51.

20. Ayub TH, Kewer-Paik MD, Debald M, Rostamzadeh B, Thiesler T, Schröder L, Barchet W, Abramian A, Kaiser C, Kristiansen G, Kuhn W, Kübler K. Accumulation of ALDH1-positive cells after neoadjuvant chemotherapy predicts treatment resistance and prognosticates poor outcome in ovarian cancer. Oncotarget. 2015:6(18):16437-48.

21. Grosse-Wilde A, Fouquier d'Hérouël A, Mclntosh E, Ertaylan G, Skupin A, Kuestner RE, del Sol A, Walters KA, Huang S. Stemness of the bybrid epithelial/mesenchymal state in breast cancer and its association with poor prognosis. PLoS One. 2015;10:e0126522.

22. Welch DR, Chen P, Miele ME, McGary CT, Bower JM, Stanbridge EJ, Weissman BE. Microcell-mediated transfer of chromosome 6 into metastatic human C8161 melanoma cells suppresses metastasis but does not inhibit tumorigenicity. Oncogene. 1994;9(1):255-62.

23. Babwah AV, Pampillo M, Min L, Kaiser UB, Bhattacharya M. Single-cell analyses reveal that KISS1R-expressing cells undergo sustained kisspeptininduced signaling that is dependent upon an influx of extracellular $\mathrm{Ca} 2+$. Endocrinology. 2012;153:5875-87.

24. Sanchez-Carbayo M, Capodieci P, Cordon-Cardo C. Tumor suppressor role of KiSS-1 in bladder cancer: lose of KiSS-1 expression is association with bladder cancer progression and clinical outcome. Am J Pathol. 2003;162:609-17.

25. Quevedo EG, Aguilar GM, Aguilar LA, Rubio SA, Martínez SE, Rodríguez IP, Corona JS, Morán Ml, Gómez RC, Moguel MC. Polymorphisms rs12998 and rs5780218 in KiSS1 suppressor metastasis gene in Mexican patients with breast cancer. Dis Markers. 2015;2015:365845.

26. Yu G, Chen Y, Ni C, Wang G, Qian J, Wang J. Reduced protein expression of metastasis- related genes (nm23, KISS1, KAl1 and p53)in lymph node and liver metastases of gastric cancer. Int J Exp Pathol. 2007;88:175-83.

27. Stein U, Walther W, Arlt F, Schwabe H, Smith J, Fichtner I, Birchmeier W, Schlag PM. MACC1, a newly identified key regulator of HGF-MET signaling, predicts colon cancer metastasis. Nat Med. 2009;15:59-67.

28. Stein U, Smith J, Walther W, Arlt F. MACC1 controls Met: what a difference an Sp1 site makes. Cell Cycle. 2009;8:2467-9.

29. Wang L, Wu Y, Lin L, Liu P, Huang H, Liao W, Zheng D, Zuo Q, Sun L, Huang $\mathrm{N}$, Shi M, Liao Y, Liao W. Metastasis-associated in colon cancer-1 upregulation predicts a poor prognosis of gastric cancer, and promotes tumor cell proliferation and invasion. Int J Cancer. 2013;133:1419-30.

30. Koelzer VH, Herrmann P, Zlobec I, Karamitopoulou E, Luqli A Stein U. Heterogeneity analysis of metastasis associated in colon cancer 1 (MACC1) for survival prognosis of colorectal cancer patients: a retrospective cohort study. BMC Cancer. 2015;15:160. 
31. Chundong G, Uramoto H, Onitsuka T, Shimokawa H, Iwanami T, Nakagawa M, Oyama T, Tanaka F. Molecular diagnosis of MACC1 status in lung adenocarcinoma by immunohistochemical analysis. Anticancer Res. 2011;31:1141-5.

32. Yue WY, Chen ZP. Does vasculogenic mimicry exist in astrocytoma? J Histochem Cytochem. 2005;53:997-1002.

33. Pàez-Ribes M, Allen E, Hudock J, Takeda T, Okuyama H, Viñals F, Inoue M, Bergers G, Hanahan D, Casanovas O. Antiangiogenic therapy elicits malignant progression of tumors to increased local invasion and distant metastasis. Cancer Cell. 2009;15:220-31.

34. Ebos JM, Lee CR, Cruz-Munoz W, Bjarnason GA, Christensen JG, Kerbel RS. Accelerated metastasis after short-term treatment with a potent inhibitor of tumor angiogenesis. Cancer Cell. 2009;15:232-9.

35. Liu X, Wang JH, Li S, Li LL, Huang M, Zhang YH, Liu Y, Yang YT, Ding R, Ke YQ. Histone deacetylase 3 expression correlates with vasculogenic mimicry through the phosphoinositide3 -kinase/ERK-MMP-laminin5Y2 signaling pathway. Cancer Sci. 2015;106:857-66.

36. Qi H, Sun B, Zhao X, Du J, Gu Q, Liu Y, Cheng R, Dong X. Wnt5apromotes vasculogenic mimicry and epithelial-mesenchymal transition via protein kinase Cain epithelial ovarian cancer. Oncol Rep. 2014;32:771-9.

37. Januchowski R, Wojtowicz K, Zabel M. The role of aldehyde dehydrogenase (ALDH) in cancer drug resistance. Biomed Pharmacother. 2013;67:669-80.

38. Shen JX, Liu J, Li GW, Huang YT, Wu HT. Mining distinct aldehyde dehydrogenase 1 (ALDH1) isoenzyme in gastric cancer. Oncotarget. 2016:7:25340-9.

39. Shao C, Sullivan JP, Girard L, Augustyn A, Yenerall P, Rodriguez-Canales J, Liu H, Behrens C, Shay JW, Wistuba II, Minna JD. Essential role of aldehyde dehydrogenase $1 \mathrm{~A} 3$ for the maintenance of non-small cell lung cancer stem cells is associated with the STAT3 pathway. Clin Cancer Res. 2014;20:4154-66.

40. Kuroda T, Hirohashi Y, Torigoe T, Yasuda K, Takhashi A, Asanuma H, Morita R, Mariya T, Asano T, Mizuuchi M, Saito T, Sato M. ALDH1-high ovarian cancer stem-like cells can be isolated from serous and clear cell adenocarcinoma cells, and ALDH1 high expression is associated with poor prognosis. PLoS One. 2013;8:e65158.

41. Jiang Y, Berk M, Singh LS, Tan H, Yin L, Powell CT, Xu Y. KiSS1 suppresses metastasis in human ovarian cancer via inhibition of protein kinase $\mathrm{C}$ alpha. Clin Exp Metastasis. 2005;22:369-76.

42. Schmid F, Burock S, Klockmeier K, Schlag PM, Stein U. SNPs in the coding region of the metastasis-inducing gene MACC1 and clinical outcome in colorectal cancer. Mol Cancer. 2012:11:49.

43. Li H, Zhang H, Zhao S, Shi Y, Yao J, Zhang Y, Guo H, Liu X. Overexpression of MACC1 and the association hepatocyte growth factor/c-Met in epithelial ovarian cancer. Oncol Lett. 2015;9:1989-96.

44. Sheng XJ, Li Z, Sun M, Wang ZH, Zhou DM, Li JQ, Zhao Q, Sun XF, Liu QC. MACC1 induces metastasis in ovarian carcinoma by upregulating hepatocyte growth factor receptor c-Met. Oncol Lett. 2014;8:891-7.

45. Hilbe W, Dirnhofer S, Oberwasserlechner F, Schmid T, Gunsilius E, Hilbe G, Wöll E, Kähler CM. CD133 positive endothelial progenitor cells contribute to the tumour vasculature in non-small cell lung cancer. J Clin Pathol. 2004;57:965-9.

46. Wang R, Chadalavad K, Wilshire J, Kowalik U, Hovinga KE, Geber A, Fligelman B, Leversha M, Brennan C, Tabar V. Glioblastoma stem-like cells give rise to tumour endothelium. Nature. 2010;468:829-33.

47. Thiery JP, Acloque H, Huang RY, Nieto MA. Epithelial-mesenchymal transitions in development and disease. Cell. 2009;139:871-90.

48. Sun T, Sun BC, Zhao XL, Zhao N, Dong XY, Che N, Yao Z, Ma YM, Gu Q, Zong WK, Liu ZY. Promotion of tumor cell metastasis and vasculogenic mimicry by way of transcription coactivation by Bcl-2 and Twist 1 : a study of hepatocellular carcinoma. Hepatology. 2011;54:1690-706.

49. Liu Z, Sun B, Qi L, Li H, Gao J, Leng X. Zinc finger E-box binding homeobox 1 promotes vasculogenic mimicry in colorectal cancer through induction of epithelial-to-mesenchymal transition. Cancer Sci. 2012;103:813-20.

50. Takeda T, Kikuchi E, Mikami S, Suzuki E, Matsumoto K, Miyajima A, Okada Y, Oya M. Prognostic role of KiSS-1 and possibility of the therapeutic modality of metastin, the final peptide of the KiSS-1 gene in urothelial carcinoma. Mol Cancer Ther. 2012;44:853-63.

\section{Submit your next manuscript to BioMed Central and we will help you at every step:}

- We accept pre-submission inquiries

- Our selector tool helps you to find the most relevant journal

- We provide round the clock customer support

- Convenient online submission

- Thorough peer review

- Inclusion in PubMed and all major indexing services

- Maximum visibility for your research

Submit your manuscript at www.biomedcentral.com/submit
Biomed Central 